\title{
Prevalence and severity of dental caries among American Indian and Alaska Native preschool children
} \author{
Patrick Blahut, DDS, $\mathrm{MPH}^{4}$ \\ 1 Oral Health Surveillance Consultant, Morro Bay, CA \\ 2 Nashville Area Indian Health Service, Nashville, TN \\ 3 University of Michigan, Ann Arbor, Ml \\ 4 Indian Health Service, Division of Oral Health, Rockville, MD
}

Kathy R. Phipps, DrPH ${ }^{1}$; Timothy L. Ricks, DMD, MPH ${ }^{2}$; Michael C. Manz, DDS, MPH, DrPH ${ }^{3}$;

\begin{abstract}
Keywords
Native American; American Indian/Alaska Native; caries; preschool children; surveillance; screening.

\section{Correspondence \\ Dr. Kathy R. Phipps, Oral Health Surveillance Consultant, 255 Bradley Avenue, Morro Bay, CA 93442. Tel.: 805-776-3393; Fax: 805-776-3393; e-mail: \\ kathyphipps1234@gmail.com. Kathy R. Phipps is an oral health surveillance consultant. Timothy L. Ricks is with the Nashville Area Indian Health Service. Michael C. Manz is with the University of Michigan. Patrick Blahut is with the Indian Health Service, Division of Oral Health.}

Received: 10/17/2011; accepted: 2/11/2011.

doi: 10.1111/j.1752-7325.2012.00331.x

Journal of Public Health Dentistry 72 (2012) 208-215

\begin{abstract}
Objectives: To describe the Indian Health Service (IHS) oral health surveillance system and the oral health status of American Indian and Alaska Native (AI/AN) children aged $1-5$ years.

Methods: A stratified probability sample of IHS/tribal sites was selected. Children were screened by trained examiners at community-based locations including medical clinics, Head Start, preschools, kindergarten, and Women, Infants, and Children (WIC). Data collection was limited to the primary dentition and included number of teeth present plus number of teeth with cavitated lesions, restorations, and extracted because of decay. Number of molars with sealants and urgency of need for dental care data were also obtained. Statistical analyses were performed with SAS (SAS Institute Inc., Cary, NC, USA). Sample weights were used to produce population estimates based on selection probabilities.

Results: A total of 8,461 AI/AN children 12-71 months of age were screened at 63 IHS/tribal sites, approximately 7 percent of the estimated IHS user population of the same age. Overall, 54 percent of the children had decay experience, 39 percent had untreated decay, 7 percent had primary molar sealants, 36 percent needed early or urgent dental care, and 6 percent needed urgent dental care. The mean of decayed, missing, or filled teeth was 3.5 (95 percent confidence interval, 3.1-3.9). The prevalence of decay experience increased with age; 21 percent of 1 -year-olds and 75 percent of 5-year-olds had a history of caries. When stratified by IHS area, there were substantial differences in the oral health of preschool children.

Conclusions: The results confirm that in the United States, AI/AN children served by IHS/tribal programs are one of the racial/ethnic groups at highest risk of caries.
\end{abstract}

\section{Introduction}

In 1957, the Indian Health Service (IHS) implemented an annual monitoring system to obtain information on the prevalence and severity of dental caries among American Indian and Alaska Native (AI/AN) dental patients. The annual monitoring system, terminated in 1978, was replaced by a series of surveys of dental patients that were conducted in 1983-1984, 1991, and 1999 (1-3).

The 1983-1984 survey raised awareness of a major problem among AI/AN children - baby bottle tooth decay now referred to as early childhood caries (ECC). Of the 0- to 4-year-old dental patients in the survey, 82 percent had a history of dental caries and 40 percent had seven or more teeth that were decayed or filled (1). As a result of this finding, IHS began extensive efforts to assist communities in controlling ECC through prevention programs that included individual counseling, community-wide education, and ongoing support for community water fluoridation (4). By 1991, the severity of dental caries in the primary dentition of AI/AN children appeared to be on the decline. The mean number of decayed, missing or filled ( $\mathrm{dmf})$ teeth among 0- to 9-yearolds decreased from 5.9 in 1983-1984 to 4.5 in 1991 (2). Unfortunately, the trend toward lower caries rates in the 
primary dentition did not continue. The mean number of dmf surfaces for 3- to 5-year-olds increased from 11.1 in 1991 to 14.6 in $1999(P<0.001)(3)$.

Although the IHS dental patient surveys have provided valuable information, using dental patient data to monitor the oral health status of preschool children may artificially inflate caries rates because parents may be more likely to bring symptomatic children with dental problems to the dental clinic than nonsymptomatic children. In addition, only a small proportion of AI/AN children 0-5 years of age visit an IHS or tribal dental clinic. According to IHS's patient monitoring system, the percentage of the IHS user population with a dental visit at an IHS or tribal dental clinic in fiscal year 2008 was only 17 percent for children $0-2$ years of age and 36 percent for those 3-5 years of age.

In order to obtain better estimates of caries rates in $\mathrm{AI} / \mathrm{AN}$ preschool populations, IHS developed an oral health surveillance system designed to obtain oral health status information periodically, every 3-5 years, from children in community-based settings rather than only from dental clinic patients. A survey of children in these settings better represents all children in the population. Data from this surveillance system will be used to monitor the oral health of AI/AN children 1-5 years of age over time and as baseline data for the multifaceted evaluation of the newly launched Early Childhood Caries Collaborative (http://www.doh.ihs.gov/ecc). The surveillance system was implemented in 2010. The purpose of this paper is to provide an overview of the surveillance system and present baseline estimates from this system describing the oral health status of AI/AN children 1-5 years of age.

\section{Methods}

\section{Background}

The IHS, an agency within the Department of Health and Human Services, is responsible for providing federal health services to AI/AN people. The operation of the IHS health services delivery system is managed through local administrative units called service units. A service unit is the primary level of health organization for a geographic area served by IHS, much like a county or city health department within a state health department. A few service units cover a number of small reservations or tribal communities, while some large reservations are divided into a number of service units. The service units are grouped into larger cultural-demographicgeographic management jurisdictions administered by area offices. The IHS is comprised 12 area offices: Aberdeen, Alaska, Albuquerque, Bemidji, Billings, California, Nashville, Navajo, Oklahoma City, Phoenix, Portland, and Tucson (Figure 1).

The IHS has carried out its responsibilities through development and operation of a health services delivery system that integrates health services delivered through IHS facilities, purchased by IHS through contractual arrangements with private providers and delivered through tribally operated programs and urban Indian health programs. In fiscal year 2009, the 12 IHS areas consisted of 166 service units, of which 104 (63 percent) were tribally operated. These 166 service units provide care to an IHS user population of over 1.5 million. The IHS user population is defined as the number of Indian registrants residing within a service delivery area with at least one face-to-face direct or contract inpatient stay, ambulatory care visit, or dental visit during the prior three fiscal years. The service delivery area for the user population is called a contract health service delivery area, and only users who live inside one can be counted as a user. The Indians residing in the service delivery areas comprise about 56 percent of all AI/AN people residing in the United States. Tucson $(25,562)$ and Nashville $(51,491)$ have the smallest user populations, while Navajo (242,331) and Oklahoma City $(318,923)$ have the largest user populations.

\section{Sample selection and screening sites}

The sampling frame consisted of all service units with an estimated 0 - to 5-year-old user population of 20 or more children (156 service units). The tribal service units in the Bemidji Area were combined to form three revised service units (Michigan, Minnesota, and Wisconsin), resulting in a sampling frame of 149 service units. A stratified probability proportional to size (PPS) cluster sampling design was used to select service units. The sampling frame was stratified by Area, and service units were sorted within each Area based on operational status (tribal or IHS) and/or state. A systematic PPS sampling was used to select service units. Systematic PPS sampling from the sorted lists provides implicit stratification on operational status and state, which ensures representation within Areas by these factors. Fifty-six service units were selected. If a service unit refused to participate, replacements were selected with a PPS random selection from within the same sampling interval as the refusing service unit. Of the 56 service units selected, 43 participated, 10 refused and were replaced by another service unit, and three refused but were not replaced. In addition, 10 service units that were not in the original sample volunteered to participate.

Because many children less than 1 year do not have teeth, we opted to screen children 1-5 years of age. Although screening a random sample of children within each service unit would be ideal, it was not logistically possible. For this reason, we opted to screen children at selected community-based sites including medical or well-child clinics, Women, Infants, and Children (WIC), Early Head Start, Head Start, tribal preschools, kindergarten, and community events. All of the community-based sites were located within the service unit's designated service delivery area. If a service unit conducted 


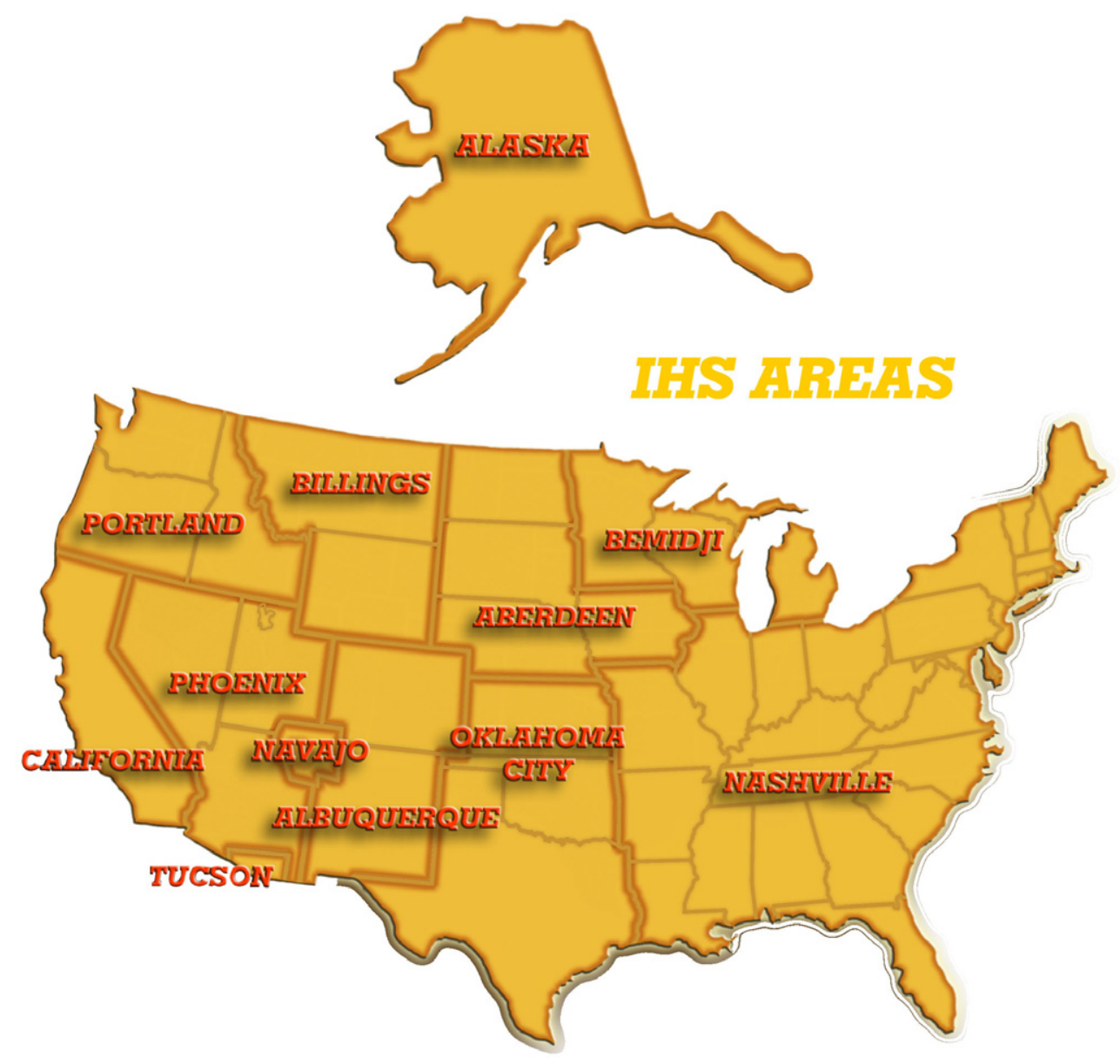

Figure 1 The 12 Indian Health Service Areas.

screenings at multiple sites, attempts were made to assure that children were only screened once. Children presenting at the dental clinics were not screened for this survey.

\section{Surveillance system indicators}

The following information was collected for each child: date of birth, gender, race, number of primary teeth present, number of primary teeth with untreated decay (cavitated carious lesions), number of primary teeth with restorations, number of primary teeth extracted because of decay, number of maxillary anterior teeth with caries experience, number of primary molars with sealants, and urgency of need for dental care. A three-level categorization was used for urgency of need for dental care: no obvious problem, early dental care needed, or urgent care needed because of pain or infection. The number of teeth with decay experience was divided by the number of erupted primary teeth to create the percentage of teeth with decay experience. We used the clinical indicator definitions and followed the data collection protocols out- lined in the Association of State and Territorial Dental Directors' publication Basic Screening Surveys: an Approach to Monitoring Community Oral Health (5). We did not collect surface-specific information, therefore, we were unable to calculate the prevalence of ECC and severe ECC as defined by the American Academy of Pediatric Dentistry (6).

Race was recorded as AI/AN or other. Any child with a recognized tribal affiliation was considered to be AI/AN. No attempt was made to determine if a child was multiracial. Only children classified as AI/AN were included in the analyses.

\section{Examiner training}

All examiners were required to attend one of the two examiner training webinars or watch the recorded webinar. The following information was included in the webinar: purpose of the survey, sampling and sample size, appropriate screening sites, survey protocol, and detailed information on clinical diagnostic criteria. Having dental examiners watch a training video has been shown to be an effective way to 
Table 1 Number of Service Units in Sampling Frame, Percentage of Service Units That Participated, Number of Children Screened by Age, and Estimated Percentage of 1- to 5-Year Old User Population Screened Stratified by IHS Area

\begin{tabular}{|c|c|c|c|c|c|c|c|c|c|}
\hline IHS area & $\begin{array}{l}\text { Service units } \\
\text { in sampling frame }\end{array}$ & $\begin{array}{l}\text { Percentage of } \\
\text { service units } \\
\text { participating }\end{array}$ & 1 year & 2 years & 3 years & 4 years & 5 years & Total & $\begin{array}{l}\text { Percentage of } \\
\text { user population }\end{array}$ \\
\hline Aberdeen & 19 & 26.3 & 84 & 103 & 199 & 254 & 77 & 717 & $7.1 \%$ \\
\hline Alaska & 9 & 44.4 & 42 & 81 & 193 & 198 & 69 & 583 & $5.1 \%$ \\
\hline Albuquerque & 9 & 44.4 & 75 & 102 & 231 & 316 & 145 & 869 & $12.1 \%$ \\
\hline Bemidji & 6 & 100.0 & 97 & 114 & 197 & 235 & 181 & 824 & $9.6 \%$ \\
\hline Billings & 8 & 100.0 & 144 & 179 & 539 & 633 & 187 & 1,682 & $26.2 \%$ \\
\hline California & 23 & 39.1 & 55 & 78 & 187 & 168 & 47 & 535 & $8.2 \%$ \\
\hline Nashville & 25 & 20.0 & 96 & 125 & 146 & 122 & 90 & 579 & $13.5 \%$ \\
\hline Navajo & 8 & 50.0 & 61 & 67 & 108 & 129 & 107 & 472 & $2.3 \%$ \\
\hline Oklahoma City & 12 & 33.3 & 83 & 111 & 190 & 175 & 115 & 674 & $2.5 \%$ \\
\hline Phoenix & 12 & 41.7 & 73 & 77 & 148 & 210 & 63 & 571 & $4.3 \%$ \\
\hline Portland & 16 & 43.8 & 75 & 62 & 148 & 222 & 87 & 594 & $7.0 \%$ \\
\hline Tucson & 2 & 100.0 & 5 & 13 & 112 & 165 & 66 & 361 & $16.9 \%$ \\
\hline Total & 149 & 42.3 & 890 & 1,112 & 2,398 & 2,827 & 1,234 & 8,461 & $6.7 \%$ \\
\hline
\end{tabular}

IHS, Indian Health Service.

standardize examiners for a Basic Screening Survey (7). No formal calibration was undertaken and examiner reliability was not assessed. A total of 178 trained dentists, dental hygienists, and dental therapists collected data.

\section{Data management and analysis}

Each Area was asked to screen a minimum of 80 children in each age year cohort from 1 to 5 years for a total of 400 children per Area. Within each Area, selected service units were asked to screen a number of children proportional to their IHS user population (i.e., larger service units were asked to screen more children than smaller service units). For a variety of reasons, not all Areas screened the minimum number of children in each year cohort (Table 1).

Service unit staff collected nonidentifiable data using paper forms, which were mailed to a central location for data entry. All statistical analyses were performed with SAS software (Version 9.2; SAS Institute Inc., Cary, NC, USA). Sample weights were used to produce population estimates based on selection probabilities and these indicated the number of children in the sampling interval each screened child represented.

The IHS oral health surveillance system is a public health activity, not human subject research. Therefore, full institutional review board (IRB) review was not necessary and written consent was not required.

\section{Results}

A total of $8,461 \mathrm{AI} / \mathrm{AN}$ children between 12 and 71 months of age were screened at 63 different IHS/tribal sites between August 2010 and January 2011. This total represents approximately 7 percent of the estimated IHS user population of the same age. The mean age of the children was 41.3 months and 52 percent were female. The majority of the children were screened at Head Start (36 percent), a medical or wellchild clinic ( 25 percent), or a non-Head Start preschool (17 percent). The distribution of children screened by age and IHS area appears in Table 1.

The prevalence of decay experience increased with age; 21 percent of 1 -year-olds and 75 percent of 5-year-olds had a history of dental caries. The prevalence of untreated decay increased from 1 to 3 years of age then stabilized at about 45 percent for those children 3-5 years. Overall, 54 percent of the children had decay experience, 39 percent had untreated decay, 7 percent had primary molar sealants, 36 percent needed early or urgent dental care, and 6 percent needed urgent dental care because of pain or infection (Table 2). Of the children with decay experience $(n=5,206), 29$ percent had all of their decay treated, 20 percent had both treated and untreated decay, and 51 percent had untreated decay only.

As with the prevalence of decay experience, mean $\mathrm{dmft}$ and mean percentage of erupted primary teeth with decay experience increased substantially with age. For 1-year-old children, mean dmft and percentage of teeth with decay experience were 0.94 and 6.4 percent, respectively, compared with 5.70 and 29.3 percent for 5-year-old children (Table 3 ). For all ages, a portion of children had over 50 percent of their teeth decayed, ranging from 2.3 percent in 1-year-olds to 22.3 percent in 5-year-olds (Table 4 ). This indicates a subpopulation at highest risk within this overall high-risk population.

Because only five 1-year-old children were screened in the Tucson Area, comparisons between Areas are limited to children 2-5 years of age. When stratified by IHS area, there were substantial differences in the oral health of preschool children 2-5 years of age with the mean $\mathrm{dmft}$ score ranging from 1.84 


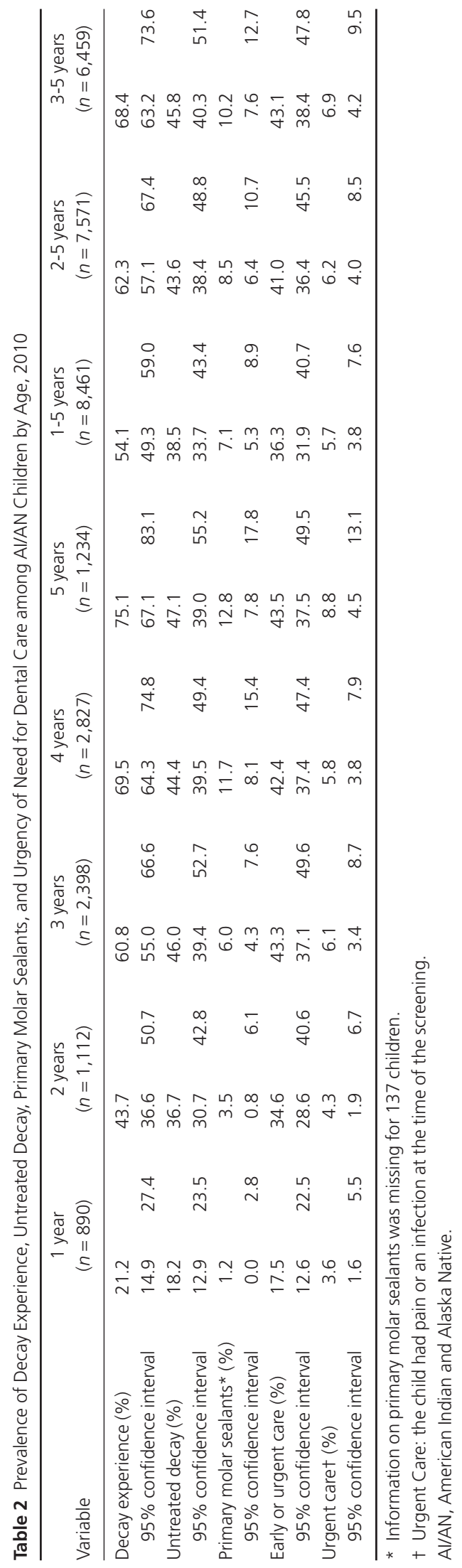

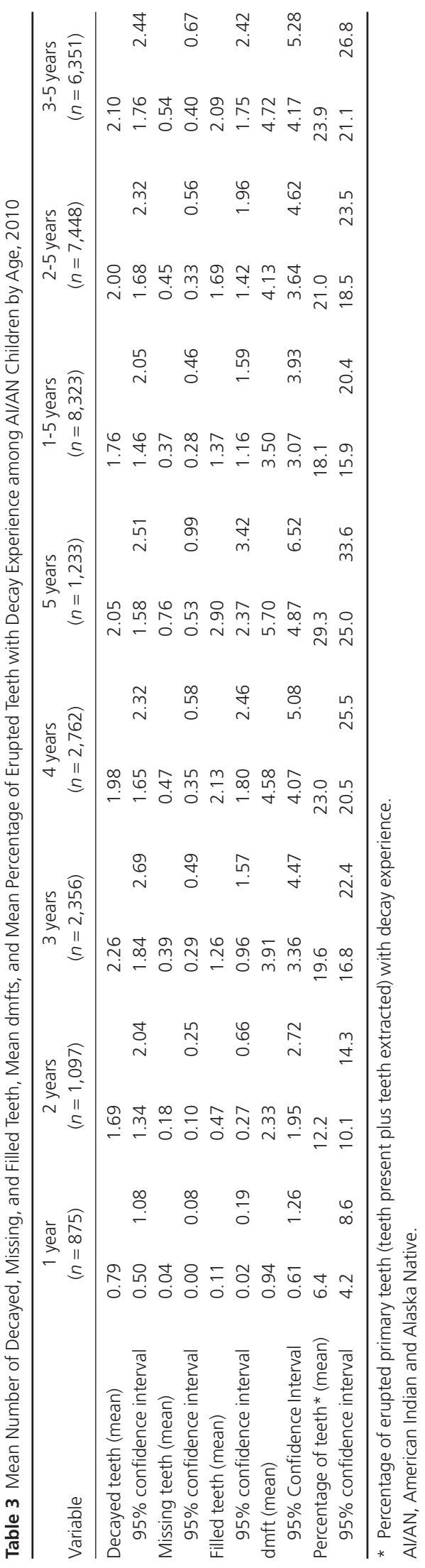

This article is a U.S. Government work and is in the public domain in the USA. 
Table 4 Percentage of Al/AN Children by Percentage of Teeth That Are Decayed, Missing, or Filled by Age, 2010

\begin{tabular}{llllll}
\hline $\begin{array}{l}\text { Percentage of teeth decayed, } \\
\text { missing, or filled }\end{array}$ & 1 year $(n=875)$ & 2 years $(n=1,097)$ & 3 years $(n=2,356)$ & 4 years $(n=2,762)$ & 5 years $(n=1,233)$ \\
\hline Caries free (0\%) & 79.0 & 56.3 & 39.1 & 30.7 & 24.9 \\
$0.1-15.0 \%$ of teeth & 5.6 & 14.8 & 18.4 & 19.0 & 17.1 \\
$15.1-30.0 \%$ of teeth & 6.6 & 12.9 & 15.3 & 18.9 & 14.4 \\
$30.1-50.0 \%$ of teeth & 6.4 & 12.5 & 15.4 & 21.3 \\
$50.1-100 \%$ of teeth & 2.3 & 3.5 & 11.8 & 13.3 & 22.3 \\
\hline
\end{tabular}

Al/AN, American Indian and Alaska Native.

to 6.52. The Oklahoma City Area had the lowest level of decay, while more isolated Areas with lower socioeconomic levels had higher rates of decay (Table 5).

\section{Discussion}

This is the first oral health survey of a national, communitybased sample of AI/AN preschool children. Because the sampling frame consisted of IHS and tribal service units, the results are not representative of all AI/AN children in the United States. As the children were screened in community-based settings rather than as patients seeking care at a dental clinic, the results are not directly comparable to any of the previous IHS oral health surveys. The results of this survey are representative of AI/AN people who receive services from IHS and tribal programs, about 56 percent of all AI/AN people.

The results confirm that in the United States, AI/AN children served by IHS/tribal programs are one of the racial/ ethnic groups at highest risk of ECC. More than 62 percent of $\mathrm{AI} / \mathrm{AN}$ children 2-5 years have experienced dental caries compared with 42 percent of Mexican-American, 32 percent of African-American, and 25 percent of non-Hispanic white children (8). However, the true burden of disease from caries is better measured by the severity of decay or the number of decayed/filled teeth ( $\mathrm{dft}$ ) which is three times higher in AI/AN preschool children $(\mathrm{dft}=3.7)$ compared with the general US population $(\mathrm{dft}=1.2)(9)$. Several other studies using convenience or state level samples have also demonstrated that AI/AN preschool children have much higher levels of caries than do their counterparts from other racial/ ethnic backgrounds (10-12).

Disparities in health among AI/AN children are not just limited to dental caries. The AI/AN postneonatal death rate is about twice that of the United States all race rate (4.2 deaths per 1,000 live births versus 2.2) and AI/AN children's deaths between the ages of 1 and 4 years occur at nearly three times the rate of children in the general population (81.2 versus 31.5 per 100,000 population) (13). An additional physical health disparity is childhood obesity and overweight. In 2001-2004, AI/AN children age 2-4 years were more than twice as likely to be at risk for overweight compared with United States all races (38.6 percent versus 15.7 percent) (14).

Despite ample documentation of high caries rates among $\mathrm{AI} / \mathrm{AN}$ preschool children, there has been little research on

Table 5 Decay Experience, Untreated Decay, dmft, and Percentage of Teeth with Decay Experience among 2-to 5-Year-Old Al/AN Children by Area, 2010

\begin{tabular}{|c|c|c|c|c|c|c|c|c|c|c|c|c|}
\hline \multirow{3}{*}{$\frac{\text { IHS area }}{\text { Aberdeen }}$} & \multicolumn{3}{|c|}{ Caries experience } & \multicolumn{3}{|c|}{ Untreated decay } & \multicolumn{3}{|c|}{$\mathrm{dmft}$} & \multicolumn{3}{|c|}{$\begin{array}{l}\% \text { of teeth with } \\
\text { decay experience }\end{array}$} \\
\hline & \multirow{2}{*}{$\begin{array}{l}\text { Percentage } \\
61.1\end{array}$} & \multicolumn{2}{|c|}{$95 \% \mathrm{Cl}$} & \multirow{2}{*}{$\begin{array}{l}\text { Percentage } \\
40.7\end{array}$} & \multicolumn{2}{|c|}{$95 \% \mathrm{Cl}$} & \multirow{2}{*}{$\frac{\text { Mean }}{3.96}$} & \multicolumn{2}{|c|}{$95 \% \mathrm{Cl}$} & \multirow{2}{*}{$\begin{array}{l}\text { Percentage } \\
20.1\end{array}$} & \multicolumn{2}{|c|}{$95 \% \mathrm{Cl}$} \\
\hline & & 49.4 & 72.7 & & 26.7 & 54.7 & & 2.65 & 5.26 & & 13.3 & 26.9 \\
\hline Alaska & 68.2 & 49.3 & 87.0 & 46.7 & 39.8 & 53.6 & 4.81 & 1.98 & 7.64 & 24.9 & 10.4 & 39.4 \\
\hline Albuquerque & 77.7 & 68.8 & 86.6 & 57.1 & 51.4 & 62.7 & 5.71 & 4.53 & 6.90 & 29.2 & 23.0 & 35.4 \\
\hline Bemidji & 53.1 & 35.9 & 70.2 & 38.0 & 28.5 & 47.4 & 3.60 & 2.12 & 5.07 & 18.2 & 10.7 & 25.6 \\
\hline Billings & 68.7 & 60.2 & 77.2 & 42.5 & 37.6 & 47.4 & 5.64 & 4.47 & 6.81 & 28.7 & 22.8 & 34.6 \\
\hline California & 54.7 & 45.1 & 64.2 & 36.9 & 24.2 & 49.6 & 2.75 & 1.87 & 3.62 & 13.8 & 9.4 & 18.2 \\
\hline Nashville & 50.5 & 38.2 & 62.7 & 34.5 & 23.2 & 45.8 & 2.79 & 1.77 & 3.81 & 14.2 & 8.9 & 19.4 \\
\hline Navajo & 85.9 & 79.8 & 92.0 & 65.8 & 50.9 & 80.7 & 6.52 & 6.17 & 6.87 & 33.2 & 31.3 & 35.0 \\
\hline Oklahoma City & 38.9 & 28.1 & 49.7 & 30.4 & 12.8 & 48.1 & 1.84 & 1.19 & 2.49 & 9.4 & 6.1 & 12.6 \\
\hline Phoenix & 67.0 & 57.9 & 76.0 & 42.2 & 33.1 & 51.4 & 4.48 & 3.59 & 5.37 & 22.6 & 18.0 & 27.3 \\
\hline Portland & 63.5 & 50.0 & 76.9 & 40.4 & 29.1 & 51.7 & 3.91 & 2.51 & 5.32 & 19.8 & 12.6 & 27.0 \\
\hline Tucson & 67.7 & 65.0 & 70.4 & 58.7 & 56.5 & 61.0 & 3.23 & 2.75 & 3.71 & 16.5 & 13.9 & 19.0 \\
\hline IHS total & 62.3 & 57.1 & 67.4 & 43.6 & 38.4 & 48.8 & 4.13 & 3.64 & 4.62 & 21.0 & 18.5 & 23.5 \\
\hline
\end{tabular}

Note: Because the Tucson Area screened only five 1-year-old children, Area comparisons are limited to children 2-5 years of age.

Al/AN, American Indian and Alaska Native; Cl, confidence interval; dmft, decayed, missing, or filled teeth; IHS, Indian Health Service. 
the underlying causes. Leake et al. (15) evaluated risk factors for severe ECC in more than 300 Canadian First Nations children 2-6 years of age and identified four protective factors: a) higher family income; b) community water fluoridation; c) drinking milk after the child began to walk; and d) drinking fruit juices after the child began to walk. The significant risks for severe ECC were consuming drinks made from flavor crystals before and after the child began to walk. A study that evaluated risk factors for caries in 77 AI children ages 12-36 months found that the following factors were associated with caries: current bottle use, giving bottle as baby falls asleep, and three or more snacks between meals (16). Given the paucity of information on why AI/AN children have such high caries rates, additional research is needed to identify the full spectrum of host, bacterial, behavioral, sociodemographic, and environmental risk factors for ECC among AI/AN infants and toddlers. The ultimate purpose of such research should be to develop strategies for preventing caries in this high-risk population by setting the stage for targeted interventions addressing identified causal factors.

We found significant differences in oral health status between IHS areas. Only 40 percent of 2- to 5-year-old children in the Oklahoma City Area had caries experience, substantially lower than other IHS areas where up to 86 percent of children had experienced caries. While these differences may be partially due to different rates of participation or sampling bias, the differences may also be due to a higher socioeconomic status among AI/AN people living in the Oklahoma City Area compared with other IHS areas. The Oklahoma City Area population has the highest percentage of AI/AN adults with a bachelor degree or higher, the lowest male and female unemployment rate, and a lower percentage of the population living below the federal poverty level (17). IHS Areas that are relatively isolated, with lower levels of educational attainment and greater poverty, tend to have greater prevalence and severity of disease. These Area differences have been noted in previous oral health surveys and have remained relatively constant over time.

While preventing ECC is important, we must also consider access to restorative services for those who develop the disease. Of the children with decay experience, only 29 percent had all of their decay treated while 51 percent had not received any restorative service. There are probably two main reasons why such a large percentage of AI/AN children have untreated decay. First, parents may not realize that their child has decay or understand the benefits of early dental care. Second, the relative geographic isolation of tribal populations and the difficulty in recruiting and retaining dentists to practice in remote IHS or tribal health facilities may limit AI/AN children's access to dental care. Approximately 15-20 percent of the dentist positions at IHS and tribal health facilities were vacant in 2010. Despite the higher oral disease rates in the $\mathrm{AI} / \mathrm{AN}$ population, in IHS there is one dentist for every 2,800
AI/AN registrants compared with one dentist for every 1,250 individuals in the general population (18). The average expenditure for oral health care in the IHS is about $\$ 61$ per person compared with about $\$ 275$ per person nationally (19). Clearly, in order to treat the underlying burden of dental disease, there must be a significant increase in resources available to IHS and tribal dental programs.

Conducting community-based oral health surveillance in a relatively small, geographically dispersed, and isolated population has inherent limitations. To contain costs, we used over $175 \mathrm{IHS} /$ tribal dental clinic staff as examiners. All examiners attended or viewed a training webinar, but we did not attempt to evaluate inter- or intra-examiner reliability. While we selected a probability sample of service units, we were not able to select a random sample of children within the service unit. Children screened were from a convenience sample of children attending medical clinics, WIC, and preschools. For this reason, our sampling error is not quantifiable although we have no reason to believe that children at these venues differ from the community as a whole. It should be noted that service units were not compensated for the time it required to participate in the survey. In some cases, vacancies in dental clinic staffing, clinical workloads, or lack of service unit resources prevented some service units from participating. In addition, some service units were not able to screen the minimum number of children for a variety of reasons including workload and limited resources. This was especially true for 1- to 2-year-olds as well as 5-year-olds. This variation in sampled numbers of children by service unit is addressed through analysis weighting but could still impact survey results. This survey is not comparable to previous IHS surveys because previous efforts all assessed patients who were present in the various IHS dental clinics seeking treatment.

The IHS recognizes that ECC is a significant health problem for AI/AN children and understands that early prevention and intervention, beginning prenatally and extending throughout the first years of life and beyond, is the best way to improve the oral health of AI/AN children. In 2010, IHS implemented an ECC Collaborative - a multifaceted program designed in part to enhance knowledge about ECC prevention and early intervention among dental providers, healthcare providers, and the community. Increasing access to oral health care and evidence-based prevention for AI/AN children requires a group effort that must include the oral health care team, medical providers, Community Health Representatives, Head Start staff, WIC program staff, and the parents of those young children at risk for the disease. The ECC Collaborative provides the entire healthcare team with the tools necessary to implement a caries prevention program and also provides a framework for early intervention using caries stabilization techniques. The results of this oral health survey will be used as baseline data for the multifaceted evaluation of the ECC Collaborative. 
A key message from the Surgeon General's report on oral health is that oral health is essential to the general health and well-being of all Americans and, given our knowledge of prevention and restorative care, can be achieved by all (20). However, not all Americans have attained a high degree of oral health. Many, including many within the AI/AN population, still endure needless pain and suffering from oral disease. To effectively address the oral health disparities outlined in this manuscript, partnerships between public, private, and tribal sectors are essential.

\section{Acknowledgments}

First, we would like to thank the 63 tribal communities and the children that took part in this survey. We would also like to thank the dentists, dental hygienists, and dental therapists who conducted the screenings and the community settings that opened their doors for the survey.

\section{Disclaimer}

The findings and conclusions in this manuscript are those of the authors, who are responsible for its content, and do not necessarily represent the views of IHS. No statement in this report should be construed as an official position of IHS or of the US Department of Health and Human Services.

\section{References}

1. Centers for Disease Control and Prevention. Dental caries in American Indian and Alaskan native children. MMWR Morb Mortal Wkly Rep. 1985;34:400-1.

2. Niendorff WJ, Jones CM. Prevalence and severity of dental caries among American Indians and Alaska Natives. J Public Health Dent. 2000;60(Suppl 1):243-9.

3. Indian Health Service. The 1999 oral health survey of American Indian and Alaska Native dental patients: findings, regional differences and national comparisons. Rockville, MD: US Department of Health and Human Services, Indian Health Service; 2001.

4. Bruerd B, Jones C. Preventing baby bottle tooth decay: eight-year results. Public Health Rep. 1996;111:63-5.

5. Association of State and Territorial Dental Directors. Basic screening surveys: an approach to monitoring community oral health. [WWW document]. URL: http://www.astdd.org/ basic-screening-survey-tool/ [accessed on August 1, 2010].

6. American Academy on Pediatric Dentistry; American Academy of Pediatrics. Policy on early childhood caries (ECC): classifications, consequences, and preventive strategies. Pediatr Dent. 2008-2009;30(7 Suppl):40-3.

7. Beltrán ED, Malvitz DM, Eklund SA. Validity of two methods for assessing oral health status of populations. J Public Health Dent. 1997;57:206-14.
8. Dental, Oral, and Craniofacial Data Resource Center. National Health and Nutrition Examination Survey 1999-2002. [WWW document]. URL: http://www.drc.gov [accessed on June 12, 2011].

9. Dye BA, Tan S, Smith V, Lewis BG, Barker LK, Thornton-Evans G, Eke PI, Beltrán-Aguilar ED, Horowitz AM, Li CH. Trends in oral health status: United States, 1988-1994 and 1999-2004. National Center for Health Statistics. Vital Health Stat 11.2007;(248):1-92.

10. Barnes GP, Parker WA, Lyon TC Jr, Drum MA, Coleman GC. Ethnicity, location, age, and fluoridation factors in baby bottle tooth decay and caries prevalence of Head Start children. Public Health Rep. 1992;107:167-73.

11. Jones DB, Schlife CM, Phipps KR. An oral health survey of Head Start children in Alaska: oral health status, treatment needs, and cost of treatment. J Public Health Dent. 1992;52: 86-93.

12. Tang JM, Altman DS, Robertson DC, O’Sullivan DM, Douglass JM, Tinanoff N. Dental caries prevalence and treatment levels in Arizona preschool children. Public Health Rep. 1997;112:319-31.

13. Indian Health Service. Trends in Indian health. 2002-2003 ed. Rockville, MD: US Department of Health and Human Services, Indian Health Service; 2008.

14. Halpern P. Obesity and American Indians/Alaska Natives. Washington, DC: US Department of Health and Human Services, Office of the Assistant Secretary for Planning and Evaluation; 2007.

15. Leake J, Jozzy S, Uswak G. Severe dental caries, impacts and determinants among children 2-6 years of age in Inuvik Region, Northwest Territories, Canada. J Can Dent Assoc. 2008;74:519.

16. Tsubouchi J, Tsubouchi M, Maynard RJ, Domoto PK, Weinstein P. A study of dental caries and risk factors among Native American infants. ASDC J Dent Child. 1995;62: 283-7.

17. Indian Health Service. Regional differences in Indian health. 2002-2003 ed. Rockville, MD: US Department of Health and Human Services, Indian Health Service; 2008.

18. Kaiser Family Foundation. Dentists per 1,000 population. [WWW document]. URL: http://www.statehealthfacts.org/ comparemaptable.jsp?ind $=691 \&$ cat $=8$ [accessed on September 17, 2011].

19. Agency for Healthcare Research and Quality. Dental Services-Mean and Median Expenses per Person with Expense and Distribution of Expenses by Source of Payment: United States, 2007. Medical Expenditure Panel Survey Household Component Data. Generated interactively. (March 14, 2011).

20. US Department of Health and Human Services. Oral health in America: a report of the surgeon general. Rockville, MD: US Department of Health and Human Services, National Institute of Dental and Craniofacial Research, National Institutes of Health; 2000. 